\title{
Influence of Aggregate Wettability with Different Lithology Aggregates on Concrete Drying Shrinkage
}

\author{
Yuanchen Guo, ${ }^{1,2}$ Jueshi Qian, ${ }^{2}$ Xue Wang, ${ }^{1}$ Zhengyi Yan, ${ }^{1}$ and Huadong Zhong ${ }^{1}$ \\ ${ }^{1}$ College of Civil Engineering, Chongqing Three Gorges University, No. 780 ShaLong Road, Wanzhou District, Chongqing 404100, China \\ ${ }^{2}$ College of Materials Science and Engineering, Chongqing University, No. 174 Shazheng Street, Shapingba District, \\ Chongqing 400030, China
}

Correspondence should be addressed to Yuanchen Guo; gyc1982@aliyun.com

Received 27 January 2015; Revised 5 April 2015; Accepted 6 April 2015

Academic Editor: Ana S. Guimarães

Copyright (C) 2015 Yuanchen Guo et al. This is an open access article distributed under the Creative Commons Attribution License, which permits unrestricted use, distribution, and reproduction in any medium, provided the original work is properly cited.

\begin{abstract}
The correlation of the wettability of different lithology aggregates and the drying shrinkage of concrete materials is studied, and some influential factors such as wettability and wetting angle are analyzed. A mercury porosimeter is used to measure the porosities of different lithology aggregates accurately, and the pore size ranges that significantly affect the drying shrinkage of different lithology aggregate concretes are confirmed. The pore distribution curve of the different coarse aggregates is also measured through a statistical method, and the contact angle of different coarse aggregates and concrete is calculated according to the linear fitting relationship. Research shows that concrete strength is determined by aggregate strength. Aggregate wettability is not directly correlated with concrete strength, but wettability significantly affects concrete drying shrinkage. In all types' pores, the greatest impacts on wettability are capillary pores and gel pores, especially for the pores of the size locating $2.5-50 \mathrm{~nm}$ and $50-100 \mathrm{~nm}$ two ranges.
\end{abstract}

\section{Introduction}

Concrete drying shrinkage is important in crack and deformation generation. For hydraulic structures, such as dams and hydropower stations, cracks caused by drying shrinkage are the main causes of leakage [1]. Previous study shows that concrete drying shrinkage does not only refers to traditional theoretical phenomena, such as moisture loss, cementitious materials shrinkage, and aggregate limitation. Aggregate constitutes approximately $70 \%-90 \%$ of concrete volume. Moreover, aggregate strength directly determines concrete strength; thus, under capillary tension theory, aggregate water absorption is the main factor that affects concrete strength and drying shrinkage [2-5]. Numerous studies have been conducted on lithology aggregates and the effect of aggregates on concrete strength and drying shrinkage [68]; reliable physical models have been established according to different theories [9]. Further research has shown that aggregate wettability is closely correlated to concrete drying shrinkage; according to the capillary bundle model based on capillary tension theory, the complex effect of internal capillary strength on aggregate absorbance has been initially solved. Based on previous research, the porosities of different lithology aggregates are measured accurately in this study using a mercury porosimeter, the pore sizes that significantly affect the drying shrinkage of different lithology aggregate concretes are verified, and the effects of different lithology aggregates on concrete drying shrinkage are summarized $[10,11]$.

\section{Experimental}

2.1. Materials. Cement P.O 42.5, superplasticizer (FDN), quartzite, marble, basalt, sandstone, and waste concrete were obtained from Wanzhou District, China. Samples from four rocks and waste concrete were collected, some cylindrical specimens with $50 \mathrm{~mm}$ diameter and $100 \mathrm{~mm}$ height were made, and wettability of the specimens was tested. Rocks and waste concrete were crushed and processed into coarse aggregates. Table 1 shows the performance parameters of the aggregate (tested in accordance with the standard of "Test Methods of Aggregate for Highway Engineering (JTG 
TABLE 1: Test results of coarse aggregate quality.

\begin{tabular}{|c|c|c|c|c|c|}
\hline $\begin{array}{l}\text { Types of coarse } \\
\text { aggregate }\end{array}$ & $\begin{array}{l}\text { Number of } \\
\text { specimens }\end{array}$ & Size $/ \mathrm{mm}$ & $\begin{array}{c}\text { Apparent } \\
\text { density } / \mathrm{kg} / \mathrm{m}^{3}\end{array}$ & Crush Index/\% & $\begin{array}{c}\text { Water absorption of } \\
\text { the dry saturation } \\
\text { surface } / \%\end{array}$ \\
\hline Sandstone & 6 & $5-20$ & 2700 & 9.4 & 0.62 \\
\hline Quartzite & 6 & $5-20$ & 2720 & 4.0 & 0.17 \\
\hline Marble & 6 & $5-20$ & 2710 & 8.9 & 0.22 \\
\hline Basalt & 6 & $5-20$ & 2950 & 4.1 & 0.28 \\
\hline RCA & 6 & $5-20$ & 2420 & 11.12 & 0.69 \\
\hline
\end{tabular}

TABLE 2: Mix proportion and compressive strength.

\begin{tabular}{lccccccccccc}
\hline \multirow{2}{*}{ Project } & $\begin{array}{c}\text { Types of coarse } \\
\text { aggregate }\end{array}$ & \multicolumn{4}{c}{ Mix proportion $/\left(\mathrm{kg} \cdot \mathrm{m}^{-3}\right)$} & \multicolumn{2}{c}{ Sand ratio } & $m_{w} / m_{c}$ & Compressive strength $(28 \mathrm{~d}) / \mathrm{MPa}$ \\
& Sandstone & 426 & 1,000 & 0 & 560 & 200 & 0.85 & 0.36 & 0.47 & 33.9 \\
SC & Quartzite & 426 & 1,000 & 0 & 560 & 200 & 0.85 & 0.36 & 0.47 & 40.2 \\
QC & Marble & 426 & 1,000 & 0 & 560 & 200 & 0.85 & 0.36 & 0.47 & 35.4 \\
MC & Basalt & 426 & 1,000 & 0 & 560 & 200 & 0.85 & 0.36 & 0.47 & 38.1 \\
BC & RCA & 426 & 0 & 1,000 & 560 & 200 & 0.85 & 0.36 & 0.47 & 34.6 \\
RAC & & & & & & & & & & & \\
\end{tabular}

E42-2005)"). The aggregates were processed into quartzite concrete (QC), marble concrete (MC), basalt concrete (BC), sandstone concrete (SC), and recycled aggregate concrete (RAC). The mix design of the cylindrical specimens is shown in Table 2. The curing is in accordance with "Standard for Test Method of Mechanical Properties on Ordinary Concrete (GB/T 50081-2002)."

2.2. Principles and Methods. The Washburn equation was essential to calculate the contact angle and create the $h^{2}-t$ curve ( $h$ is water rising height in cm over time $t$ ), but measuring height " $h$ " accurately was difficult because of irregular internal pore distribution. Thus, the $h^{2}-t$ curve was converted to the relationship between $m^{2}$ and $t$, and the effective radius $R_{m}$ was introduced according to capillary tension theory; thus, concrete contact angle can be calculated according to linear fitting relationship and the following formulas.

The specimens were dried to a constant weight and placed in a self-made contact angle testing equipment [7]. Wettability was analyzed through the Washburn method; thus, the relationship between the wettability of aggregates and that of aggregate concrete was determined, along with the relationship between the strength of aggregates and that of aggregate concrete. The same grain sizes for QC, MC, $\mathrm{BC}, \mathrm{SC}$, and RAC were considered. The aggregate porosity $\varepsilon$ of these concretes could be measured using an AutoPore 9500 mercury porosimeter; the $\varepsilon$ of QC, MC, BC, SC, and RAC were measured similarly. The $28 \mathrm{~d}$ strength and drying shrinkage value of the different aggregates were tested. Finally, the pore distribution curve of the different coarse aggregates and coarse aggregate concretes was summarized according to (1)-(3), and the contact angle was calculated:

$$
m^{2}=\left(\varepsilon \cdot \rho_{W} \cdot \sum s_{i}\right)^{2} \cdot\left(\frac{\gamma R \cos \theta}{2 \eta}\right) t
$$

where $m$ is the weight in $g$ of the water sunk into RAC over time $t, \varepsilon$ is the porosity of RAC to the decimal meter, $\rho_{W}$ is the water density, $s_{i}$ is the $i$ th sectional area of the cylindrical capillary tube, $\gamma$ is liquid surface tension in dyne $/ \mathrm{cm}, \eta$ is the viscosity of the liquid in $\mathrm{Pa} \cdot \mathrm{s}, R$ is the effective capillary radius in $\mathrm{cm}$, and $\theta$ is contact angle in ${ }^{\circ}$. Slope $k$ is computed with (2) and is used to obtain contact angle $\theta$ in (3):

$$
\begin{aligned}
& k=\left(\varepsilon \cdot h \cdot \rho_{W} \cdot \sum s_{i}\right)^{2} \cdot \frac{\gamma R_{m} \cos \theta}{2 \eta} \\
& \theta=\arccos \left(\frac{2 k \eta}{\gamma R_{m}}\right) .
\end{aligned}
$$

The $m^{2}-t$ curve is almost a straight line according to these formulas.

Experimental methods of the mechanical properties testing are in accordance with "Standard for Test Method of Mechanical Properties on Ordinary Concrete (GB/T 500812002)"; experimental methods of the drying shrinkage test are in accordance with "Standard for Test Method of Mechanical Properties on Ordinary Concrete (GB/T 50081-2002).”

\section{Results and Discussion}

3.1. Strength of Different Coarse Aggregate Concretes. The C30 natural concrete mix proportion is used as reference. Table 2 shows the mix design and $28 \mathrm{~d}$ compressive strength of the concrete.

In Table 1, "NA" is natural aggregates. As shown in Table 1, the order of the compressive strength of the concrete from the strongest to the weakest is QC, BC, MC, SC, and RAC. According to Table 2, the strength of the different lithology aggregates of concrete in descending order is QC, BC, MC, RAC, and SC. Therefore, the concrete strength is determined by the aggregate strength. The water absorption of different 
TABLE 3: Pore distribution ratios of different coarse aggregates.

\begin{tabular}{|c|c|c|c|c|c|}
\hline \multirow{2}{*}{ Pore radius/nm } & \multicolumn{5}{|c|}{ Distribution value/\% } \\
\hline & Sandstone & Quartzite & Marble & Basalt & RAC \\
\hline$>10,000$ & 18.1 & 75.0 & 63.3 & 15.1 & 4.0 \\
\hline $10,000-100$ & 19.9 & 25.0 & 29.0 & 27.0 & 31.8 \\
\hline $100-50$ & 18.4 & 0 & 7.7 & 6.4 & 14.0 \\
\hline $50-5$ & 42.4 & 0 & 0 & 45.9 & 41.5 \\
\hline $5-3$ & 1.2 & 0 & 0 & 5.6 & 8.7 \\
\hline $3-100$ sum & 62.0 & 0 & 7.7 & 57.9 & 64.2 \\
\hline
\end{tabular}

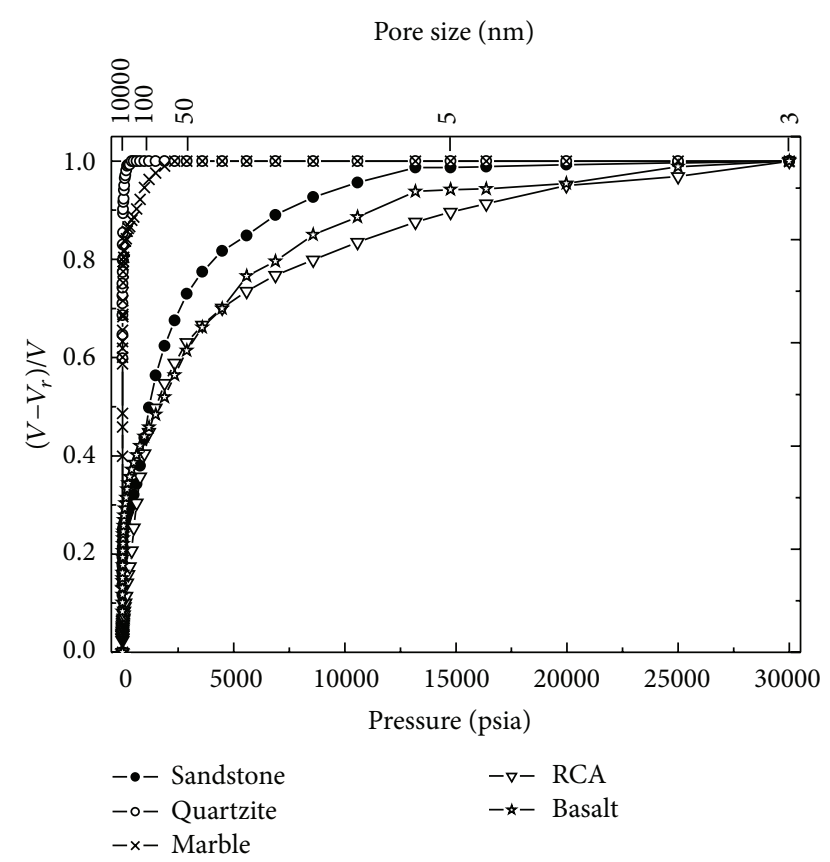

Figure 1: Curve of the pore distribution ratios of different coarse aggregates.

lithology aggregates from the largest to the smallest is RAC, SC, BC, MC, and QC, which illustrates that the aggregate strength is closely correlated with water absorption, and both are inversely proportional.

3.2. Distribution Value and Curve of Different Coarse Aggregates. Pores with a size of 3-100 nm significantly affect concrete drying shrinkage according to the physical model established in previous research [12]. Table 3 shows the pore distribution ratios of different lithology aggregates, which are tested using a mercury porosimeter and are summarized via a statistical method. The curve is shown in Figure 1.

As shown in Table 3 and Figure 1, the distribution ratio of the pore size 3-100 $\mathrm{nm}$ of the different coarse aggregates in descending order is RAC, SC, BC, MC, and QC. Water absorption has the same descending order; therefore, pore size distribution is the main factor that affects water absorption, given the $3-100 \mathrm{~nm}$ pore size.

3.3. Distribution Value and Curve of Different Coarse Aggregate Concretes. Open-pore volume of the specimen whose radius is between $r$ and $r+d r$ is expressed as $d V$; thus the pores size distribution function (in volume) can be shown in the following equation:

$$
f(r)=\frac{d V}{V d r} .
$$

In formula $\operatorname{Pr}=-(2 \sigma \cos \theta), \sigma$ and $\theta$ are constant, so $P d r+r d P=0$, where $P$ is applied pressure, $\mathrm{Pa}, r$ is radius of pore, $\mathrm{nm}, \sigma$ is surface tension of mercury, $\mathrm{N} \cdot \mathrm{m}^{-1}$, the surface tension of mercury is $0.48 \mathrm{~N} \cdot \mathrm{m}^{-1}$ at $20^{\circ} \mathrm{C}, \theta$ is the wetting angle of mercury solid surface, ${ }^{\circ}$, and the wetting angle of mercury-cement material is $125^{\circ}$. Therefore

$$
f(r)=-\frac{P}{r V} \frac{d V}{d P} .
$$

Because of the pore volume what is measured directly with the instrument is the volume whose radius is greater than $r$, which can be expressed as $V-V_{r}$, where $V$ is total open-pore volume, and $V_{r}$ is open-pore volume whose radius is smaller than $r$ in specimen. If pushed mercury-content curve depicted the function of $V-V_{r}$ versus $P$, then the curve slope $d\left(V-V_{r}\right) / d P=-d V / d P$ can be measured by the experiment, so the above formula can be written as

$$
f(r)=\frac{P}{r V} \frac{d\left(V-V_{r}\right)}{d P} .
$$

The right-hand side value in (6) is known or can be measured, and the derivative in (6) can be solved by graphic differentiation to obtain $f(r)$. Finally, the pore size distribution curve can be obtained by drawing point $r$ corresponding to the $f(r)$ value.

For convenience, directly measured data can be plotted in the cumulative pore volume variation diagram of $\left(V-V_{r}\right) / V$ versus $P$ (as shown in Figure 2), and the corresponding $r$ values are attached to the $P$-axle. Thus, taking several $\Delta d$ intervals according to need in the figure and finding the increment of $\left(V-V_{r}\right) / V$ in each corresponding interval, the pore size distribution table can be listed [12], as shown in Table 4. The curve is illustrated in Figure 2.

As shown in Table 4 and Figure 2, for the different lithology aggregate concretes, the $3-100 \mathrm{~nm}$ pore distribution ratio of RAC is the largest. The distribution ratios of SC, QC, and $\mathrm{BC}$ are equal, and $\mathrm{MC}$ has the lowest ratio. According to Tables 2 and 4, pore porosity and concrete strength are closely correlated, and both are usually inversely proportional. 
TABLE 4: Pore distribution ratios of different coarse aggregate concretes.

\begin{tabular}{lccccc}
\hline Pore radius/nm & \multicolumn{3}{c}{ Distribution value/\% } & QC & RAC \\
& MC & SC & 13.1 & 6.7 \\
10,000 & 33.4 & 17.0 & 20.5 & 24.1 & 22.1 \\
$10,000-100$ & 29.6 & 14.5 & 9.5 & 12.0 & 13.5 \\
$50-50$ & 13.4 & 14.1 & 47.3 & 50.0 & 6.8 \\
$5-3$ & 23.6 & 1.8 & 9.6 & 6.6 & 8.6 \\
$3-100$ sum & 0 & 68.5 & 66.4 & 71.2 \\
\hline
\end{tabular}

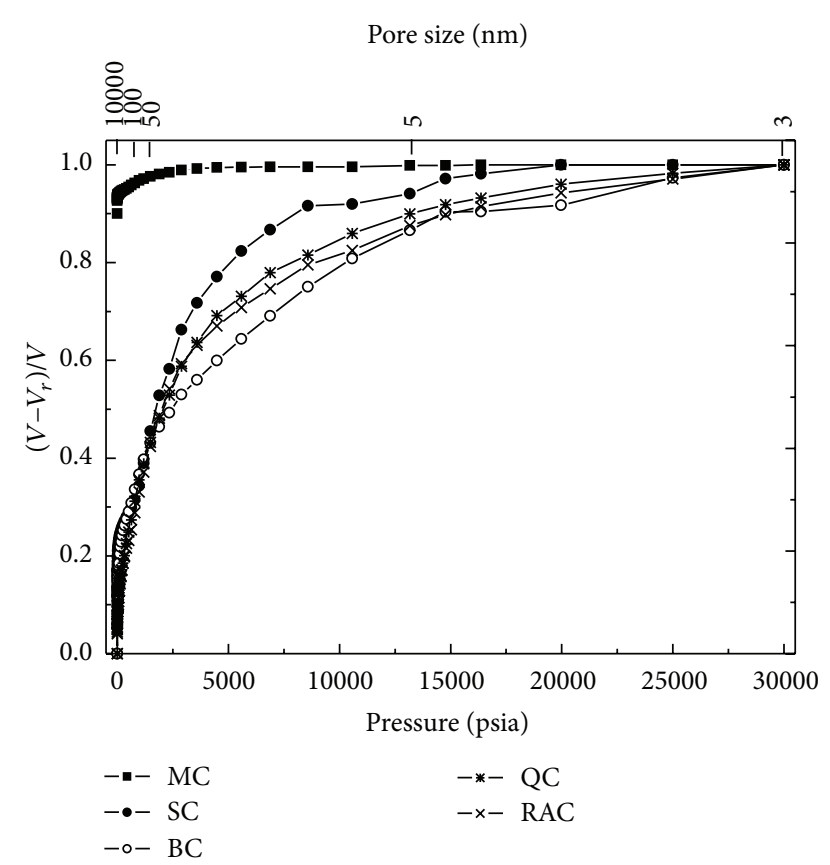

FIGURE 2: Curve of pore distribution ratios of different coarse aggregate concretes.

3.4. Wettability Curve of Different Coarse Aggregate Concretes and Contact Angle of the Curve. According to the tested pore distribution ratio and (1)-(3), the $m^{2}-t$ curve can be summarized, as shown in Figure 3.

Figure 3 shows that the different lithology aggregates and concrete moisture absorption performance can be divided into two stages; moisture content is large at the prophase, moisture content and time have a rough logarithmic relation, and moisture and time are inevitably correlated. The curve flattens in the later period. This phenomenon is mainly caused by the large pore, and connected capillary bundles form in the previous hydration process stage of concrete, during which both water absorption and water loss are large. Along with the hydration process of concrete, both pore and capillary bundle shrink gradually, and concrete drying shrinkage stabilizes.

The contact angle of the different coarse aggregates and concretes can be calculated according to Figure 3 and the theoretical formulas (the method is according to the document [7]).

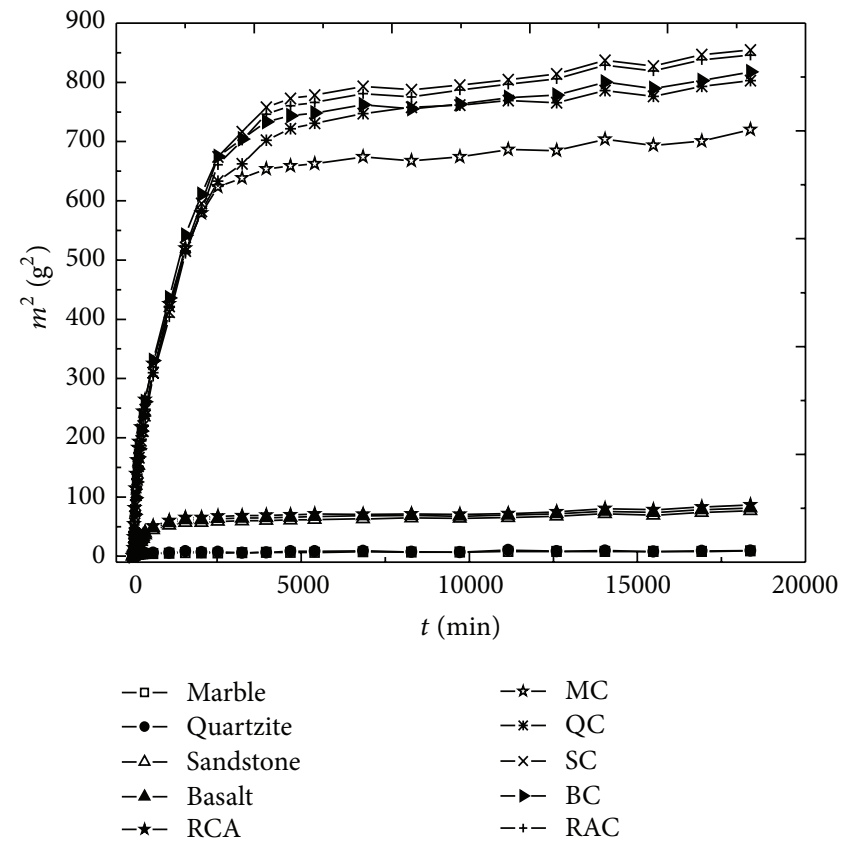

FIGURE 3: Wettability curve of different coarse aggregates and concretes.

TABLE 5: Contact angle of different coarse aggregates and concretes.

\begin{tabular}{lccc}
\hline Name & $k$ & $\cos \theta$ & $\theta /^{\circ}$ \\
\hline Marble & 0.0222 & 0.0090 & 89.5 \\
Sandstone & 0.1620 & 0.1745 & 80.0 \\
Quartzite & 0.1280 & 0.0889 & 84.9 \\
Basalt & 0.1438 & 0.0271 & 88.4 \\
RAC & 0.1616 & 0.0642 & 86.3 \\
MC & 1.0276 & 0.3745 & 68.0 \\
SC & 1.6245 & 0.7682 & 39.8 \\
QC & 1.6056 & 0.6916 & 46.2 \\
BC & 1.3619 & 0.5201 & 58.7 \\
RAC & 0.9869 & 0.2724 & 74.2 \\
\hline
\end{tabular}

Table 5 shows the aggregates in descending order according to the contact angle: MC, BC, RAC, QC, and SC. When the moisture absorption ratios of the aggregates and the $m^{2}-t$ curve are combined, the aggregate contact angle and moisture absorption become inversely proportional, which 


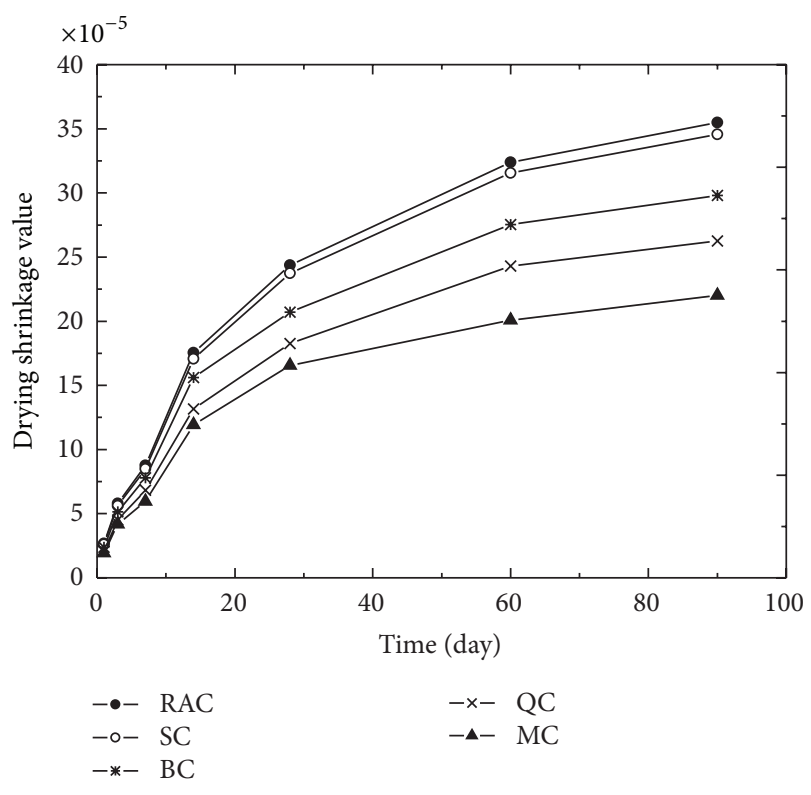

FIGURE 4: Curve of drying shrinkage of different coarse aggregate concretes.

are influenced by shape, and the RAC ingredient can be disregarded. The different coarse aggregate concretes are arranged in descending order based on the contact angle as follows: MC, BC, QC, and SC. Concrete contact angle is directly determined by the aggregate contact angle.

3.5. Drying Shrinkage Characteristics of Different Lithology Aggregates and Concretes. The drying shrinkage value of prepared concrete at different stages is tested on the basis of the drying shrinkage characteristics of different lithology aggregate concretes, as indicated by the curve in Figure 4.

Figure 4 shows the drying shrinkage from the largest to the smallest as RAC, SC, BC, QC, and MC; thus, the 3$100 \mathrm{~nm}$ pore distribution and wettability are roughly directly proportional to concrete drying shrinkage.

As can been seen from Figures 2 and 4 and Table 4, in all types' pores, the greatest impacts on wettability are capillary pores and gel pores, especially for pores with sizes ranging from $2.5 \mathrm{~nm}$ to $50 \mathrm{~nm}$ and from $50 \mathrm{~nm}$ to $100 \mathrm{~nm}$.

\section{Conclusions}

The main physical factors that affect concrete drying shrinkage are wettability, contact angle, aggregate water absorption, and pore distribution. The following conclusions are drawn.

Concrete strength is determined by aggregate strength, and both types of strength are directly proportional. Aggregate wettability is determined by contact angle and the 3$100 \mathrm{~nm}$ pore size distribution; thus, surface water absorption is also influenced.

Aggregate contact angle and surface water absorption are inversely proportional, and concrete drying shrinkage is significantly affected by contact angle, wettability, and water absorption rate. Thus, the wettability and water absorption rate of different lithology aggregates are roughly directly proportional to concrete drying shrinkage.

Concrete drying shrinkage shows obvious periodic regularity, which is closely related to the concrete hydration process.

The ingredients and characteristics of recycled concrete materials are complex and difficult to compare with other different lithology aggregates to obtain the regularity. However, this study shows that the pore porosity of recycled aggregates determines drying shrinkage, which is consistent with general regularity.

\section{Conflict of Interests}

The authors declare that they do not have any commercial or associative interest that represents a conflict of interests in connection with the work submitted.

\section{Acknowledgments}

This project was supported by the Project of National Natural Science Foundation of China (51202304), the Natural Science Foundation Project of CQ CSTC (cstc2012jjA50005), Project funded by China Postdoctoral Science Foundation (2014M552320), and Scientific, Technological Talents' Special Funds of Wanzhou District and Scientific and Technological Research Program of Chongqing Municipal Education Commission (KJ1401016).

\section{References}

[1] Z. He, C. Qian, and G. Qian, "Influence of concrete constituents on drying shrinkage of concrete at same compressive strengths," Journal of Advanced Microscopy Research, vol. 9, no. 1, pp. 50-53, 2014.

[2] J. Zhang, Y. D. Han, and Y. Gao, "Effects of water-binder ratio and coarse aggregate content on interior humidity, autogenous shrinkage, and drying shrinkage of concrete," Journal of Materials in Civil Engineering, vol. 26, no. 1, pp. 184-189, 2014.

[3] N. Jafarifar, K. Pilakoutas, and T. Bennett, "Moisture transport and drying shrinkage properties of steel-fibre-reinforcedconcrete," Construction \& Building Materials, vol. 73, no. 10, pp. 41-50, 2014.

[4] J. Zhang, Y. D. Han, Y. Gao, and Y. Luosun, "Integrative study on the effect of internal curing on autogenous and drying shrinkage of high-strength concrete," Drying Technology, vol. 31, no. 5, pp. 565-575, 2013.

[5] Z. Jun, G. Yuan, H. Yudong, and W. Qiang, "Modeling on shrinkage stress in early-age concrete pavements," International Journal of Pavement Research \& Technology, vol. 6, no. 4, pp. 250-260, 2013.

[6] Y. Shi, Y. Dong, Z. Liang et al., "Dry shrinkage deformation of cement mortar and concrete containing different aggregate," Yangtze River, vol. 44, no. 20, pp. 57-60, 2013.

[7] Y. C. Guo, X. Wang, and Y.-X. He, "Isothermal sorption of recycled aggregate concrete and its influence on drying shrinkage," Journal of Building Materials, vol. 15, no. 3, pp. 386-390, 2012.

[8] Z. X. Xing, "Regression analysis between aggregate species and the strength influence coefficient of macroporous concrete without sand," Concrete, vol. 11, pp. 73-79, 2012. 
[9] D. Boucherit, S. Kenai, E. Kadri, and J. M. Khatib, "A simplified model for the prediction of long term concrete drying shrinkage," Journal of Civil Engineering, vol. 18, no. 7, pp. 2196-2208, 2014.

[10] N. Y. Ho, Y. P. K. Lee, W. F. Lim et al., "Efficient utilization of recycled concrete aggregate in structural concrete," Journal of Materials in Civil Engineering, vol. 25, no. 3, pp. 318-327, 2013.

[11] I. Sallehan, "Mechanical strength and drying shrinkage properties of concrete containing treated coarse recycled concrete aggregates," Construction \& Building Materials, vol. 68, no. 10, pp. 726-739, 2014.

[12] Y. C. Guo, J. S. Qian, and X. Wang, "Pore structure and influence of recycled aggregate concrete on drying shrinkage," Mathematical Problems in Engineering, vol. 2013, Article ID 912412, 7 pages, 2013. 

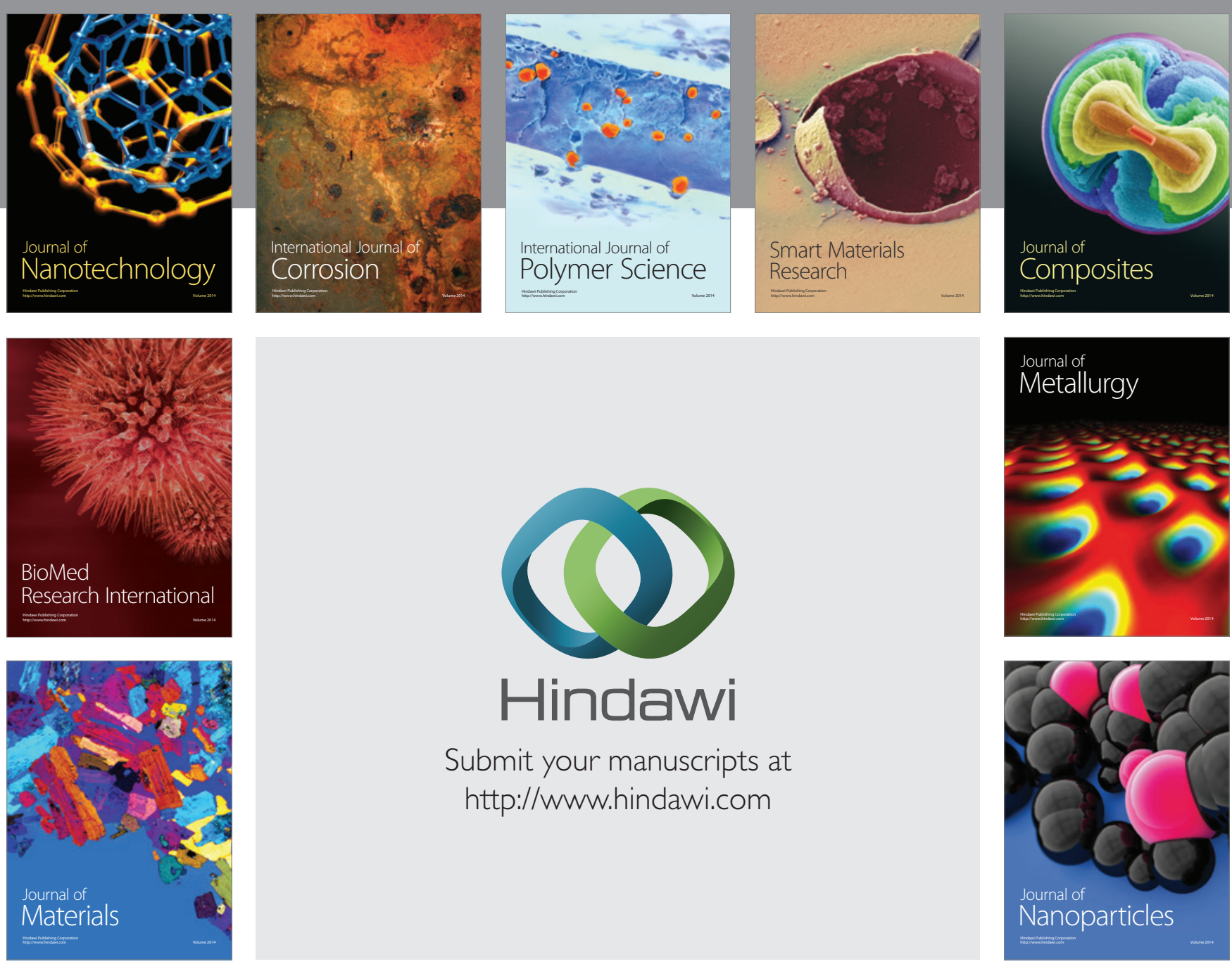

Submit your manuscripts at http://www.hindawi.com
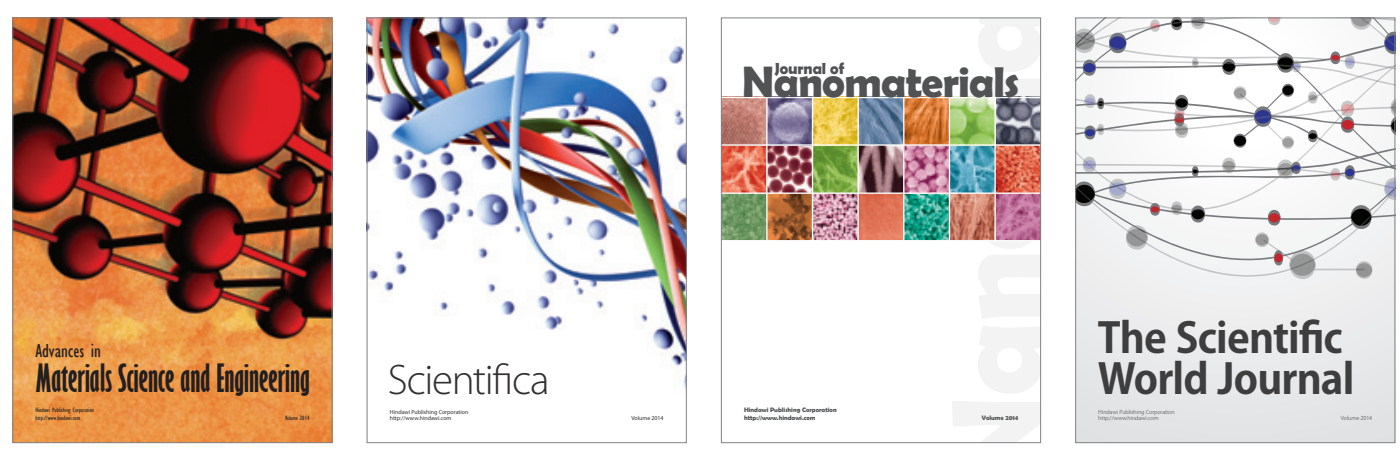

\section{The Scientific World Journal}
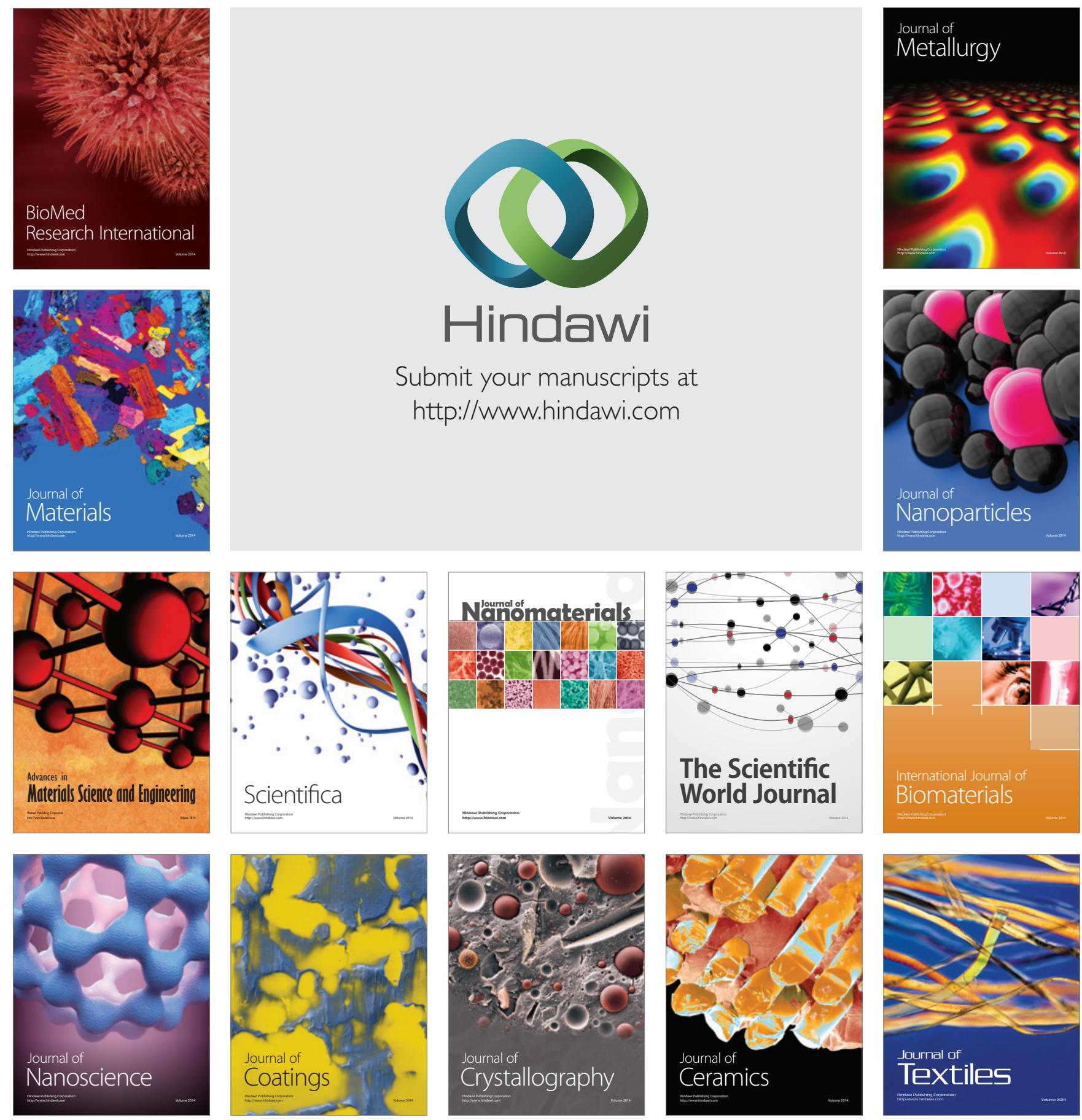